\title{
AN IMPROVED METHOD FOR HIGH IMPEDANCE FAULT DETECTION IN MEDIUM VOLTAGE NETWORKS
}

\author{
Sonja Ravlić, Ante Marušić, Juraj Havelka
}

Original scientific paper

This paper presents a set of rules for an intelligent algorithm of high impedance fault detection by observing the phase to ground voltage, phase to phase current and harmonics of fault current. Several techniques to detect high impedance faults already exist for example current injection in the neutral, superposing voltage signals, harmonic analysis, neural networks. The main disadvantage of all methods is that the normal system activity may cause false tripping of the protection device. Our goal is to give a set of rules for an algorithm that can make a secure decision that a particular feeder event is high impedance fault. The set of rules was carried out from simulation results simulated in MATLAB. The proposed approach was trained and tested with 200 data sets and provides excellent results.

Keywords: fault detection; Fourier transform; high impedance fault; medium voltage network

Unaprijeđena metoda detekcije visokoomskih kvarova u mrežama srednjeg napona

Izvorni znanstveni članak Ovim člankom predstavljen je skup pravila za inteligentni algoritam detekcije visokoomskih kvarova promatranjem faznih napona i struja, kao i harmonika struje kvara. Nekoliko metoda detekcije visokoomskih kvarova već postoji kao što su npr. injektiranje struje, superpozicija signala napona, harmonička analiza, neuronske mreže. Glavni nedostatak svih postojećih metoda detekcije visokoomskih kvarova leži u tome da zaštitni uređaji prepoznaju normalne sklopne operacije u mreži kao visokoosmski kvar (neželjena prorada zaštitnih uređaja). Cilj istraživanja bio je postaviti skup pravila za inteligentni algoritam koji može donijeti sigurnu odluku da li je do kvara došlo ili ne. Navedeni skup pravila je dobiven na temelju rezultata simulacijskog modela razvijenog u programskom paketu MATLAB. Navedeni pristup je ispitan s 200 skupova ulaznih podataka te daje odlične rezultate.

Ključne riječi: detekcija kvara; Fourierova transformacija; mreža srednjeg napona; visokoomski kvar

\section{Introduction}

High impedance single-phase to earth faults (HIFs) in medium voltage networks are difficult to detect using conventional overcurrent, ground fault relays and some versions of distance relaying schemes [1]. This kind of faults is hard to detect by monitoring equipment because their presence result with only slight increase in phase to ground current and phase to ground voltage, thus can be confused with normal increases in load [2]. HIF is defined as unwanted electrical contact between an energized conductor and a high impedance surface such as asphalt road, sand, grass or tree [3]. This fault has a small current ranging from a few $\mathrm{mA}$ to tens of amperes [4]. The failure of HIFs detection leads to serious threat in electric shock to human beings and potential fire hazards [5].

HIF is a very complex phenomenon and exhibits highly nonlinear behaviour [6]. High impedance faults are inherently nonlinear and always result in distorted current, so harmonic analysis is critical in the evaluation and determination of HIFs $[2 \div 7]$.

The detection of high impedance faults is certainly difficult [8]. In fact, as it was recognized in the conclusions of the Working Group D15 of the IEEE Power Engineering Society [9], "no matter what method is used, not all high impedance faults (HIF) are detectable" and "practically, it is impossible to detect all HIFs and at the same time achieve a high degree of security against false outputs". In the same sense, CIGRE Study Committee B5 reported that "all utilities have had and regularly continue to have undetected HIF records" and concluded that HIF detection is an important technical challenge that requires further research and efforts in order to achieve more reliable and effective solutions [10].
There are different ways of detecting and handling high impedance earth faults: direct measurement of the electric quantities of the power system, energy and randomness algorithms, harmonic analysis, neural networks, wavelet analysis and chaotic pattern analysis [11]. The features of the high impedance faults are extracted and invested using fuzzy logic, genetic algorithm and Kalman filtering, as well [11].

A detection technique is reliable and secure when it is capable of perfectly identifying and distinguishing the high impedance faults from other transients in network [12]. The problem is that normal switching events (such as feeder switching, capacitor banks switching) generate similar components as high impedance faults which results in false tripping of the protection devices [11]. Certain relay manufactures commercialized protection devices with HIF detection functions, but utilities that have tested them agree that the performance is not satisfactory [10].

In order to see the influence HIF has on the network, a simulation model using MATLAB Simulink was made. Our goal was to observe phase to ground voltage, phase to ground current, phase to phase voltage, phase to phase current and zero sequence current of the line in case of high impedance fault and in case of normal system activities. First, third, fifth and seventh harmonic of the zero sequence current was observed with the same target. Fig. 1 shows a one-line diagram of the analysed system. Location of measurements in substation is shown in Fig. 1 , as well.

A total of 200 simulations for various line lengths, fault resistances, the moment when a fault occurs were observed. 200 simulations gave 2600 data that were used to establish a set of rules and to train the algorithm for high impedance fault detection. The proposed approach 
was trained and tested with 200 data sets and provides excellent results.

This paper presents a new approach for HIF detection using Fourier transform and design of intelligent system. The aim of this paper is to give an algorithm which discriminates high impedance faults against regular switching and switching of shunt capacitors.

\section{Matlab Simulink simulation model}

In order to describe the behaviour of the network during high impedance faults and during normal system activity simulation model was made using MATLAB SimPowerSystem software. SimPowerSystems provides component libraries and analysis tools for modelling and simulating electrical power systems [13]. With the intention to control results given by simulation models the mathematical model was created as well. The comparison of the simulation model results and calculated values show match [6].

A simulation model consists of: three-phase $110 \mathrm{kV}$ source, network transformer $110 / 20 \mathrm{kV}$, medium voltage cables and overhead lines, series load and element that represents a high impedance fault/normal system activity [14]. In this simulation model network transformer is earthed through arc suppression coil.

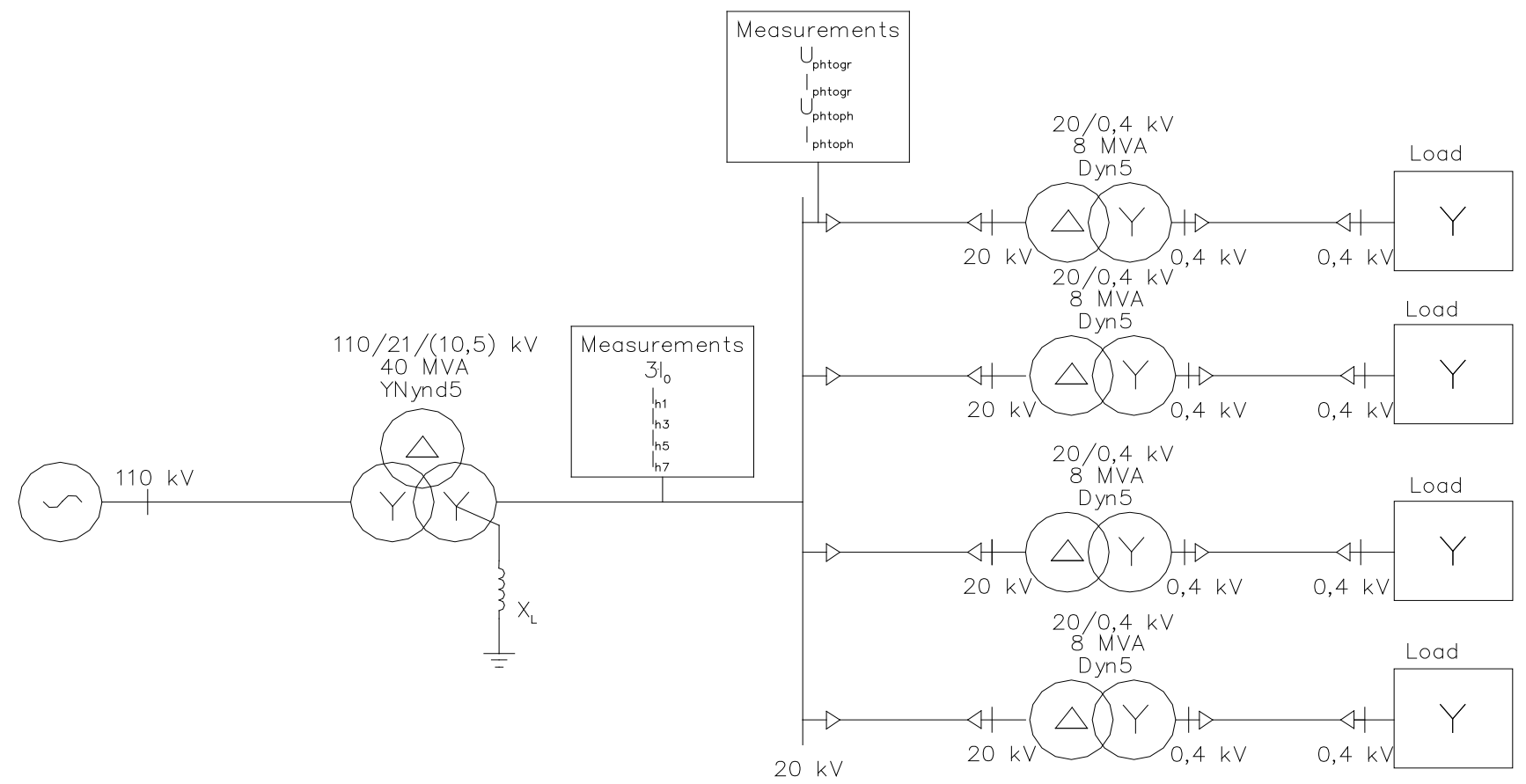

Figure 1 One-line diagram of the analysed system

The different simulation conditions taken into consideration were:

- $\quad$ Three phase load switching (on and off);

- Three phase line without load switching (on and off);

- Three phase capacitor banks switching (on and off);

- $\quad$ Direct single line fault to earth $\left(R_{\mathrm{f}}=0 \Omega\right)$;

- High impedance fault $\left(R_{\mathrm{f}}=4000 \Omega, 15000 \Omega\right.$, $50000 \Omega$ );

- Various power line lengths (1 km, $20 \mathrm{~km}$ and $40 \mathrm{~km})$;

- Various moments when an event occurs $(t=5 \mathrm{~ms}, 10$ $\mathrm{ms})$.

This model shows phase to ground currents and voltages as well as zero sequence harmonics of the observed line during fault/switching events and results can help in the decision whether the high impedance fault occurred or not. The idea is to develop an intelligent system that can process multiple algorithms and multiple parameters for secure high impedance fault detection. Fig. 2 shows the behaviour of phase to ground current in case of HIF and Fig. 3 behaviour of phase to ground voltage. It is evident that HIF cannot be detected just by observing specified values. The harmonics amplitude and angle give superior results for detection of HIFs to the fundamental component. The amplitude and phase of the first, third, fifth and seventh harmonic of the zero sequence line current were extracted using Fourier transform in order to decide whether fault occurred $[15 \div 16]$. The goal is to combine all the results in intelligent algorithm which can be implemented in commercial electric power analysis software and commercial protection devices.

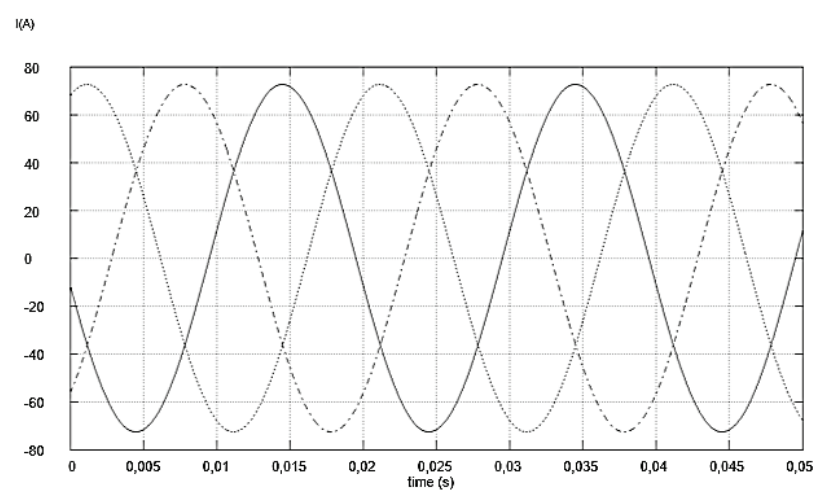

Figure 2 Phase to ground current of faulted line in case of high impedance fault 
A set of indicators will be given to distinguish fault situations from other situations. The results obtained from simulation model will be foundation for algorithm which can improve the limitations of the present protection technology.

The main goal is to detect HIFs, discriminate them from normal system activities and to improve the reliability and security of the electric grid.

$\mathrm{u}(\mathrm{kV})$

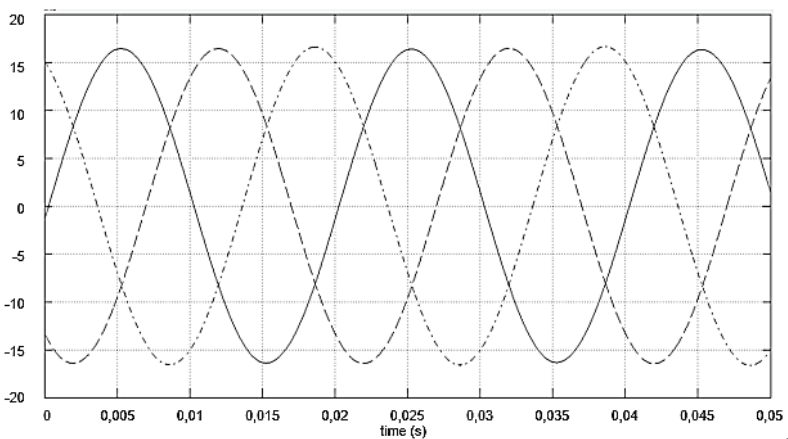

Figure 3 Phase to ground voltage of faulted line in case of high impedance fault

\subsection{High impedance fault model}

HIFs on electrical power distribution system involve arcing and nonlinear characteristics of fault impedance which cause a stochastic nonlinear current. The Emanuel arc model was presented in 1990. It is based on theoretical components and laboratory measurements [12]. Fig. 4 shows Emanuel arc model. In this model, the arc in HIF is modelled using two DC sources, connected as anti-paralleled by two diodes. Many researchers have been using this model and have tried to complete it. In 2014, a new model for high impedance fault in electrical distribution system was presented [12]. It uses several Emanuel arc models in parallel that combined produce HIF current similar to real recorded HIF current. Fig. 5 shows improved HIF model. In order to see the behaviour of the network in case of high impedance fault and to get as many different situations both models were taken into account.

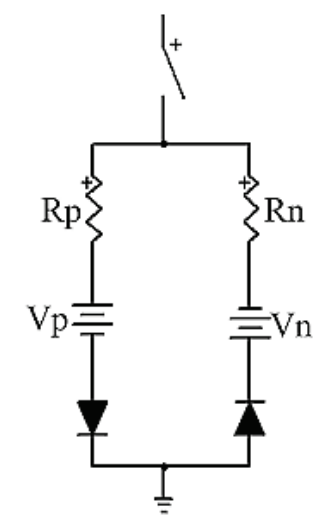

Figure 4 Emanuel arc model

Fig. 6 shows simulated zero sequence line current results in case of the classic Emanuel arc model. Fig. 7 shows simulated results of zero sequence line current in case of the improved Emanuel arc model.

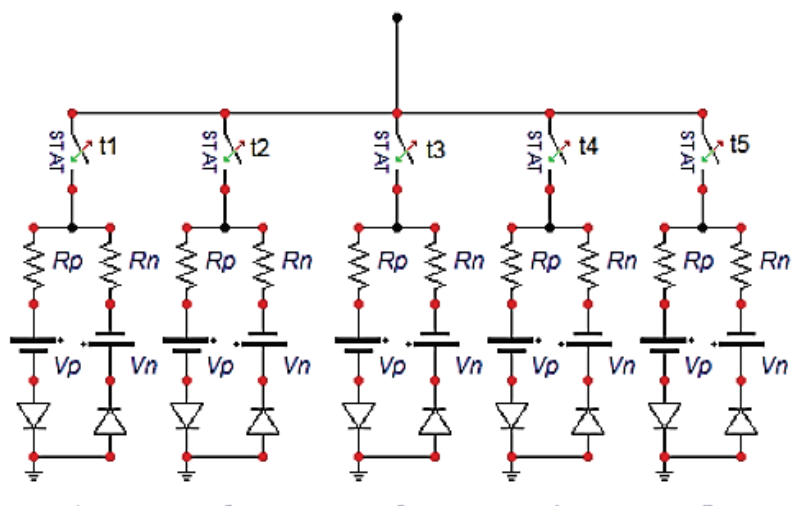

1

3

4

Figure 5 Improved Emanuel arc model

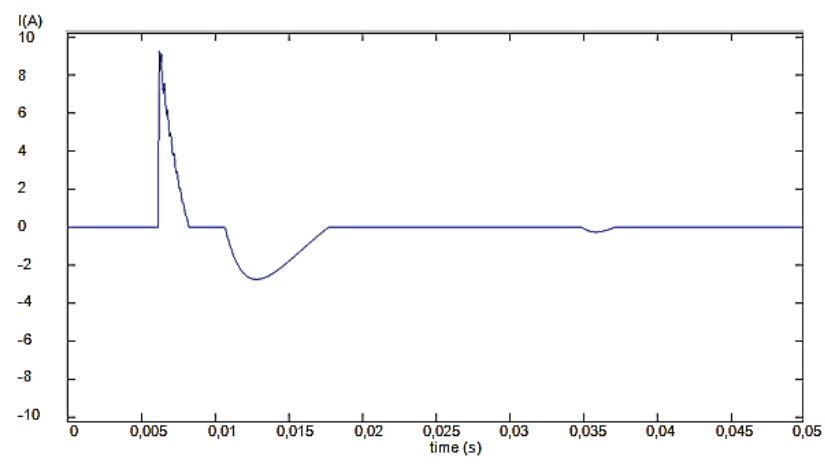

Figure 6 Zero sequence current in case of HIF (classic Emanuel arc model)

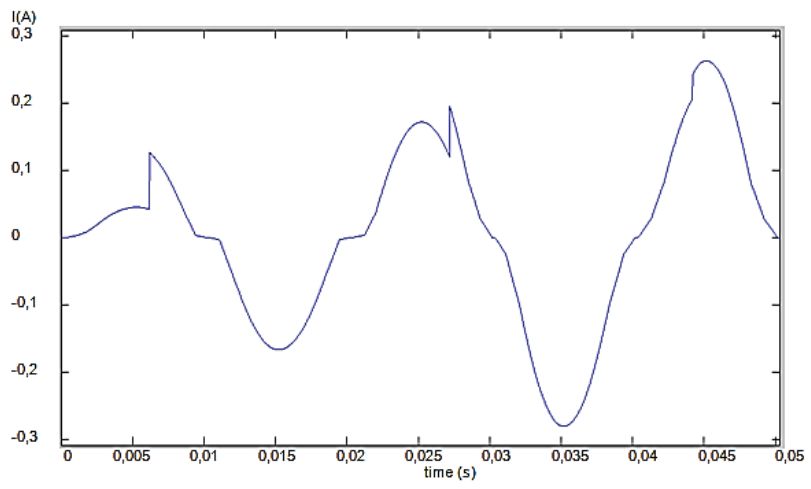

Figure 7 Zero sequence current in case of HIF (improved Emanuel arc model)

\section{Simulation result}

Results from 200 simulated events in Matlab were compared in order to make a set of rules for the high impedance detection algorithm. The following figures will show simulation results in case of three phase line without load switching and in case of high impedance fault. The main goal is to show that just by observing amplitude of the zero sequence current and their harmonics it is not possible for the protection device to decide whether the fault occurred. That is the reason why phase to phase voltages and currents need to be incorporated in algorithm as well. 


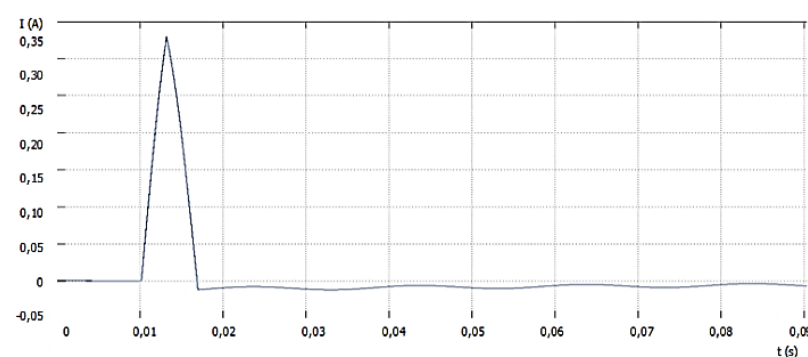

a)

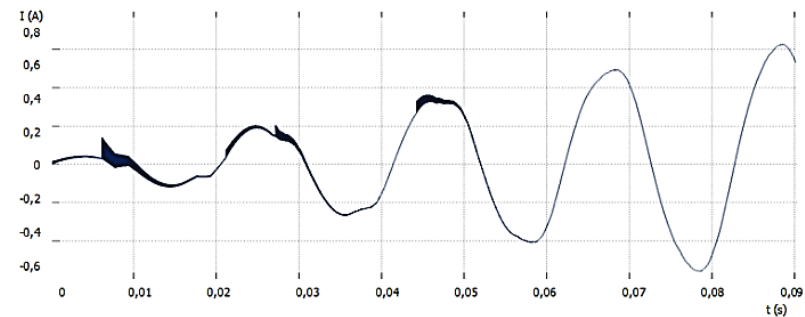

b)

Figure 8 Zero sequence current in case of: a) Three phase line without load switching, b) HIF (improved Emanuel arc model)

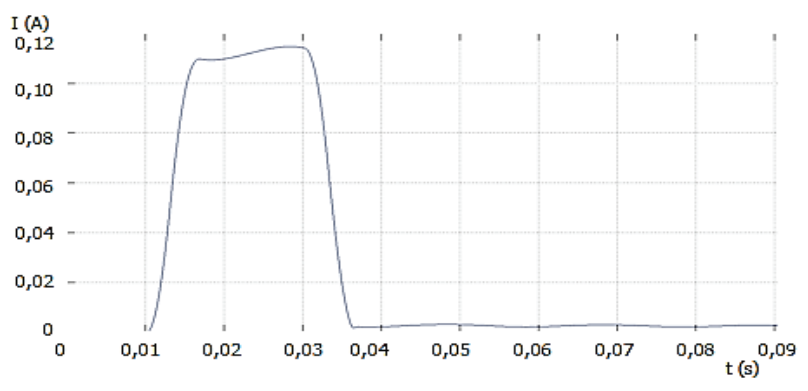

a)

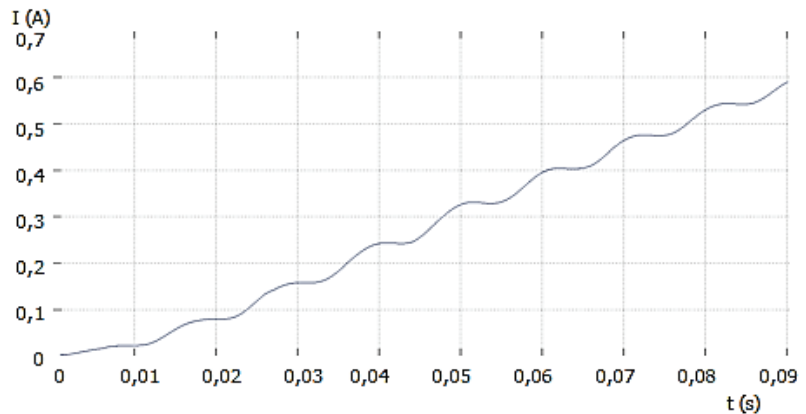

b)

Figure 9 First harmonic of zero sequence current in case of: a) Three phase line without load switching, b) HIF (improved Emanuel arc model)

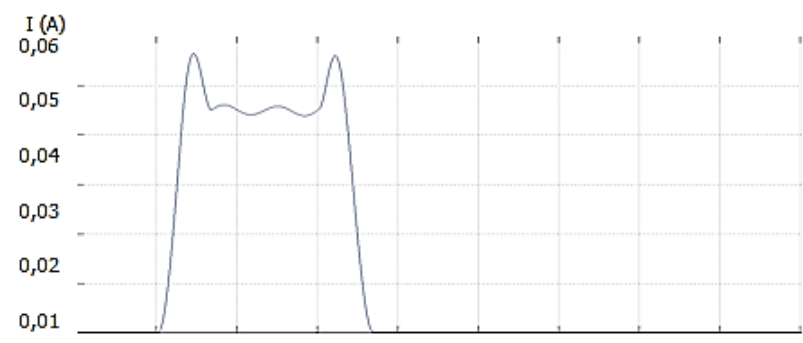

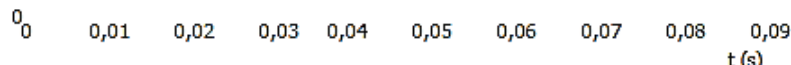

a)

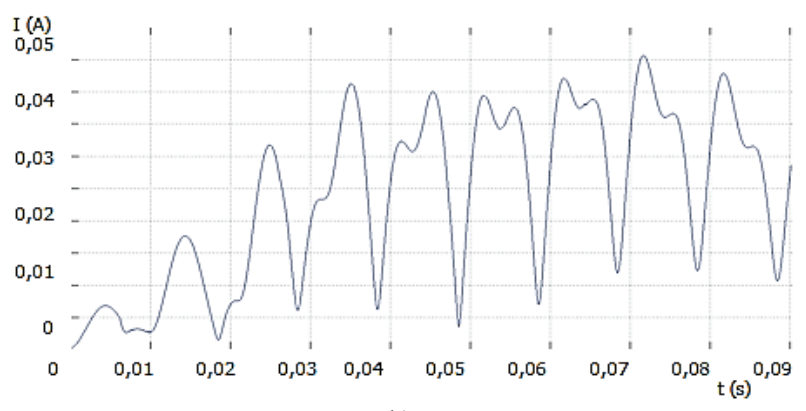

b)

Figure 10 Third harmonic of zero sequence current in case of: a) Three phase line without load switching, b) HIF (improved Emanuel arc model)

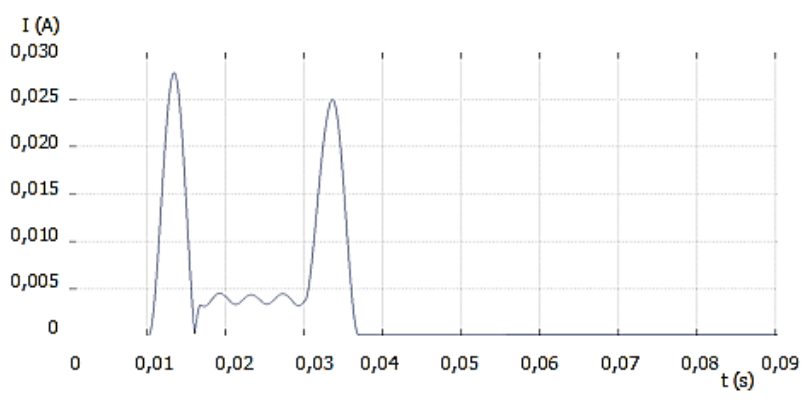

a)

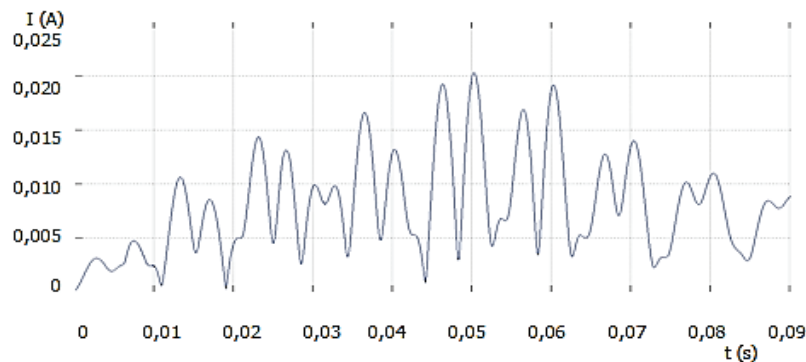

b)

Figure 11 Fifth harmonic of zero sequence current in case of: a) Three phase line without load switching, b) HIF (improved Emanuel arc model)

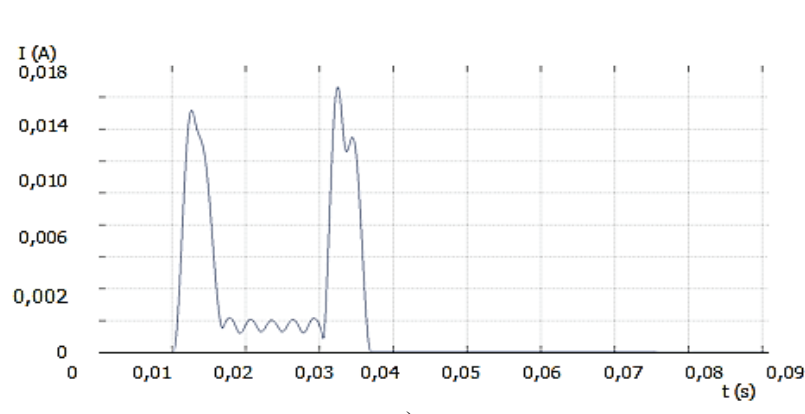

a)

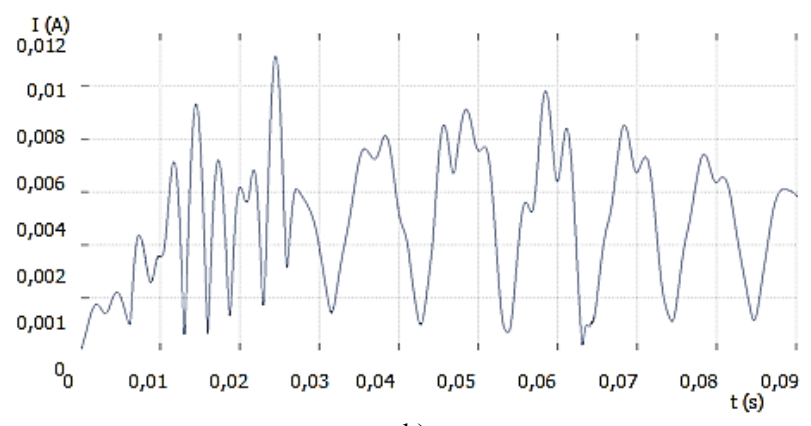

b)

Figure 12 Seventh harmonic of zero sequence current in case of: a) Three phase line without load switching, b) HIF (improved Emanuel arc model) 


\section{Discussion}

After analysing all the results from 200 simulated events in MATLAB, a set of rules for an algorithm of HIF detection and differentiation from normal switching condition was established $[17,18] . U_{\text {phtogr }}$ is phase to ground voltage, $I_{\text {phtogr }}$ is phase to ground current, $3 \cdot I_{0}$ refers to zero sequence line current, harmonics refer to first, third, fifth and seventh harmonic of the zero sequence current. Factor $k$ relates to the ratio of phase to ground voltage after and before the simulated event occurs in the network (overvoltages). The proposed algorithm should include three important parts: input data, features generation and network activity (fault/not fault). In order to combine the proposed algorithm in electrical power system, zero sequence current relay with harmonic component needs to be installed. Phase to ground current and voltage, as well as zero sequence current of the line (amplitude and phase of first, third, fifth and seventh harmonic) should be measured and compared before $\left(t_{1}\right)$ and after network event $\left(t_{2}\right)$. Data obtained from the simulation model gave us rules for HIF detection. The goal is to achieve a set of rules for protection devices that can be used in power system. The set of rules for determination weather the high impedance fault occurred or not is given in the following lines.

Note: In some cases during event $U_{\text {phtogr }}$ ratio was higher than 1 and lower than 1 for the same event depending on simulation conditions (for example various power line lengths and various moments when an event occurred). In that case $U_{\text {phtogr }}$ ratio is identified as $k<1$ OR $k \geq 1$.

Three phase load switching (on)

$$
k>1
$$

$U_{\text {phtogr }}\left(t_{2}\right)>U_{\text {phtogr }}\left(t_{1}\right)$

$I_{\text {phtogr }}\left(t_{2}\right)>I_{\text {phtogr }}\left(t_{1}\right)$

Harmonics $\approx 0$

$3 \cdot I_{0} \approx 0$

Three phase load switching (off)

$k<1$ OR $k \geq 1$

$U_{\text {phtogr }}\left(t_{2}\right)<U_{\text {phtogr }}\left(t_{1}\right)$

$I_{\text {phtogr }}\left(t_{2}\right)<I_{\text {phtogr }}\left(t_{1}\right)$

Harmonics $\neq 0$

$3 \cdot I_{0} \neq 0$

Three phase line without load switching (on)

$$
k>1
$$

$U_{\text {phtogr }}\left(t_{2}\right)>U_{\text {phtogr }}\left(t_{1}\right)$

$I_{\text {phtogr }}\left(t_{2}\right)>I_{\text {phtogr }}\left(t_{1}\right)$

Harmonics $\approx 0$

$3 \cdot I_{0} \approx 0$

Three phase line without load switching (off)

$k<1$ OR $k \geq 1$

$U_{\text {phtogr }}\left(t_{2}\right)<U_{\text {phtogr }}\left(t_{1}\right)$

$I_{\text {phtogr }}\left(t_{2}\right)<I_{\text {phtogr }}\left(t_{1}\right)$

Harmonics $\neq 0$

$3 \cdot I_{0} \neq 0$

Three phase shunt capacitors switching (on)

$k>1,4$

$U_{\text {phtogr }}\left(t_{2}\right)>U_{\text {phtogr }}\left(t_{1}\right)$

$I_{\text {phtogr }}\left(t_{2}\right)>I_{\text {phtogr }}\left(t_{1}\right)$

Harmonics $\approx 0$

$3 \cdot I_{0} \approx 0$
Three phase shunt capacitors switching (off)

$1 \leq k<1,01$

$U_{\text {phtogr }}\left(t_{2}\right) \geq U_{\text {phtogr }}\left(t_{1}\right)$

$I_{\text {phtogr }}\left(t_{2}\right)=I_{\text {phtogr }}\left(t_{1}\right)$

Harmonics $\approx 0$

$3 \cdot I_{0} \approx 0$

Direct single line fault to earth

$k>1,72$

$U_{\text {phtogr }}\left(t_{2}\right)>U_{\text {phtogr }}\left(t_{1}\right)$

$I_{\text {phtogr }}\left(t_{2}\right)>I_{\text {phtogr }}\left(t_{1}\right)$

Harmonics $\neq 0$

$3 \cdot I_{0}>200 \mathrm{~A}$

High impedance fault to earth

$$
k>1
$$

$U_{\text {phtogr }}\left(t_{2}\right)>U_{\text {phtogr }}\left(t_{1}\right)$

$I_{\text {phtogr }}\left(t_{2}\right)=I_{\text {phtogr }}\left(t_{1}\right)$

Harmonics $>0$

$3 \cdot I_{0} \neq 0$

A novel technique for detecting high impedance faults and discrimination HIFs against regular network switching showed very satisfying results. After testing 200 various conditions that can occur in distributive networks advantages of algorithm were confirmed. In the event of a high impedance fault the feeder's response becomes different from the normal operations. The normal network operations taken into consideration were three phase load switching (on and off); three phase line without load switching (on and off) and three phase capacitor banks switching (on and off).

\section{Conclusion}

High impedance fault detection is a significant problem for protection engineers. This paper gives the reasons that led to the development of a new algorithm for high impedance fault detection and discriminations against regular network switching. The proposed set of rules allows the algorithm to recognize if HIF has occurred. The set of rules for the algorithm was obtained from hundreds of simulation results. It is expected that HIF detection in future will be even more important due to higher demands for reliability of power supplied to customers. Future work should further investigate the combination of the proposed set of rules for the algorithm with existing algorithms for high impedance fault location. The algorithm can be combined with existing commercial electrical power system analysis software to discriminate clearly between fault and non-fault events.

\section{Acknowledgements}

The authors gratefully acknowledge the support and assistance of Ravel d.o.o. and Faculty of Electrical Engineering, University of Zagreb.

\section{Appendix}

Parameters of simulation model are given here:

Network frequency: $50 \mathrm{~Hz}$

Source: Three-phase $110 \mathrm{kV}$ ideal source

Network transformer: 110/21/10,5; 40 MVA; YNynD5

Load power: $20 \mathrm{MVA}$

Load power factor: 0,95 
Medium voltage $(20 \mathrm{kV})$ cables and overhead lines length variation: $1 \mathrm{~km}, 20 \mathrm{~km}$ and $40 \mathrm{~km}$

Table 1 Specifications of medium voltage power line

\begin{tabular}{|c|c|c|c|}
\hline \multirow{2}{*}{$\begin{array}{c}\text { Power line } \\
\text { type }\end{array}$} & $\begin{array}{c}\text { Resistance per } \\
\text { unit length } \\
(\Omega / \mathrm{km})\end{array}$ & $\begin{array}{c}\text { Inductance } \\
\text { per unit } \\
\text { length } \\
(\mathrm{H} / \mathrm{km})\end{array}$ & $\begin{array}{c}\text { Capacitance } \\
\text { per unit } \\
\text { length } \\
(\mathrm{F} / \mathrm{km})\end{array}$ \\
\hline \multirow{2}{*}{ Cable } & $R_{\mathrm{d}}=0,206$ & $L_{\mathrm{d}}=0,39 \times 10^{-3}$ & $C_{\mathrm{d}}=0,251 \times 10^{-6}$ \\
\cline { 2 - 4 } & $R_{0}=0,7749$ & $L_{0}=1,702 \times 10^{-3}$ & $C_{0}=0,439 \times 10^{-6}$ \\
\hline
\end{tabular}

Classic Emanuel model parameters:

$R_{\mathrm{n}}=9000 \Omega, R_{\mathrm{p}}=12000 \Omega, V_{\mathrm{n}}=4000 \mathrm{~V}, V_{\mathrm{p}}=4500 \mathrm{~V}$

Improved Emanuel model parameters:

Table 2 Improved Emanuel model parameters

\begin{tabular}{|c|c|c|c|c|c|}
\hline Parameter & Arc 1 & Arc 2 & Arc 3 & Arc 4 & Arc 5 \\
\hline$t(\mathrm{~ms})$ & 6,2 & 21,1 & 44,2 & 44,2 & 27,2 \\
\hline$R_{\mathrm{n}}(\mathrm{k} \Omega)$ & 90 & 129 & 135 & 135 & 140 \\
\hline$R_{\mathrm{p}}(\mathrm{k} \Omega)$ & 120 & 130 & 130 & 130 & 140,1 \\
\hline$V_{\mathrm{n}}(\mathrm{V})$ & 4000 & 8000 & 7500 & 7500 & 490 \\
\hline$V_{\mathrm{p}}(\mathrm{V})$ & 4500 & 8100 & 7600 & 7600 & 510 \\
\hline
\end{tabular}

\section{References}

[1] Samantaray, S. R.; Dash, P. K. High Impedance Fault Detection in Distribution Feeders Using Extended Kalman Filter and Support Vector Machine. // European Transactions on Electrical Power. 20, 3(2010), pp. 382-393. DOI: 10.1002/etep.321

[2] Uriarte, F. M. Modeling, Detection and Localization of High Impedance Faults in Low-Voltage Distribution Feeders, Master of science thesis, Virginia Tech Polytechnic Institute and State University, Blacksburg, VA, 2003.

[3] Zhang, Y.; Wang, Z.; Zhang, J. Universal characteristics of faults in complex power system. // International Review of Electrical Engineering (IREE). 6, 3(2011), pp. 1474-1482.

[4] Eldin, A. H.; Abdallah, E.; Mohamed, N. Detection of High Impedance Faults in Medium Voltage Distribution Networks using Discrete Wavelet Transform. // $22^{\text {nd }}$ International Conference on Electricity Distribution, Stockholm, Sweden session 3, June 10-13, 2013.

[5] Tawafan, A. H.; Sulaiman, M. B.; Ibrahim, Z. B. Adaptive Neural Subtractive Clustering Fuzzy Inference System for the Detection of High Impedance Fault on Distribution Power System. // International Journal of Artificial Intelligence. 1, 2(2002), pp. 63-72.

[6] Ravlić, S.; Marušić, A. Simulation Models for Various Neutral Earthing Methods in Medium Voltage Systems. // Procedia Engineering. 100, 12(2015), pp. 1182-1191. DOI: 10.1016/j.proeng.2015.01.482

[7] Mansour, M. M.; Wahab, M. A. A.; Soliman, W. M. Petri Nets Fault Diagnosis System for a Large Power Station and its Transmission Lines. // International Review of Electrical Engineering (IREE). 8, 2(2013), pp. 820-831

[8] Sagastabeitia, K. J.; Zamora, I.; Mazón, A. J.; Aginako, Z.; Buigues, G. Phase Asymmetry: A New Parameter for Detecting Single-Phase Earth Faults in Compensated MV Networks. // IEEE Transactions on power delivery, 26, 4(2011), pp. 2251-2258. DOI: 10.1109/TPWRD.2011.2141155

[9] Power System Relaying Committee, Working Group D15 of the IEEE Power Eng. Soc., High impedance fault detection technology, March 1996.

[10] CIGRE Study Committee B5, Report of Working Group 94, High impedance faults, July 2009.
[11] Hanninen, S.; Lehtonen, M. Method for Detection and Location of Very Resistive Earth Faults. // European Transactions on Electrical Power. 9, 5(1999), pp. 285-291. DOI: $10.1002 /$ etep.4450090501

[12] Sedighi, A. R. A New Model for High Impedance Fault in Electrical Distribution Systems. // International Journal of Scientific Research in Computer Science and Engineering. 2, 4(2014), pp. 1-5.

[13] Mathworks, Accelerating the pace of engineering and science, http://www.mathworks.com/products/simpower/, (20.8.2015)

[14] Bellan, D. Statistical Characterization of Harmonic Emissions in Power Supply Systems. // International Review of Electrical Engineering (IREE). 9, 4(2014), pp. 803-810. DOI: 10.15866/iree.v9i4.1099

[15] Dan, A. M.; Raisz, D. Fault Location of the Harmonic Content of the Residual Fault Current during Single-Phase to Ground Faults in Compensated Networks. // International Conference on Renewable Energies an Power Quality, Granada, Spain, March 23-25, 2010.

[16] Curk, J. Higher Harmonics in Earth Fault Currents in MV Insulated Neutral Networks Help Detect and Evaluate the Fault. // Mako Cigre, Ohrid, Macedonia, September 26-29, 2004.

[17] Sheng, Y.; Rovnyak, S. M. Decision Tree-Based Methodology for High Impedance Fault Detection. // IEEE Transactions on Power Delivery. 19, 2(2004), pp. 533-536. DOI: 10.1109/TPWRD.2003.820418

[18] Welfonder, T.; Leitloff, V.; Feuillet, R.; Vitet, S. Location Strategies and Evaluation of Detection Algorithms for Earth Faults in Compensated MV Distribution Systems. // IEEE Transactions on Power Delivery. 15, 4(2000), pp. 11211128. DOI: $10.1109 / 61.891492$

[19] Masa, A. V.; Werben, S.; Maun, J.C. Incorporation of DataMining in Protection Technology for High Impedance Fault Detection. // IEEE Power and Energy Society General Meeting, San Diego, California, July 22-26, 2012

\section{Authors' addresses}

\section{Sonja Ravlic, PhD Student}

Ravel Ltd.,

Brajkovićev priklaz 13, 10000 Zagreb, Croatia

sonja.ravlic@ravel.hr

\section{Ante Marušić, Full Professor}

University of Zagreb,

Faculty of Electrical Engineering and Computing, Unska 3, 10000 Zagreb, Croatia ante.marusic@fer.hr

\section{Juraj Havelka, Assistant Professor}

University of Zagreb,

Faculty of Electrical Engineering and Computing,

Unska 3, 10000 Zagreb, Croatia

juraj.havelka@fer.hr 